\title{
Itinerário terapêutico de famílias de crianças com doenças crônicas.
}

\section{Janis Marcondes Rodríguez*, Luciana Palacio Fernandes Cabeça, Luciana de Lione Melo.}

\section{Resumo}

Introdução: itinerário terapêutico é o movimento que indivíduos/grupos realizam com o objetivo de preservar ou recuperar a saúde. Objetivo: compreender o itinerário terapêutico de famílias de crianças com doenças crônicas hospitalizadas. Método: estudo fenomenológico, realizado em um hospital universitário, com 10 famílias de crianças com doenças crônicas que participaram de entrevista fenomenológica com a questão norteadora - 'Conte-me a respeito do caminho que você (e sua família) percorreu em busca de atendimento de saúde para o seu filho antes de chegar nesse hospital'. Resultados: emergiram quatro categorias temáticas - Caminhando em busca de assistência à saúde do filho - o início da saga; Percebendo-se vulneráveis diante do Sistema Único de Saúde; Da dificuldade para conseguir acesso à saúde à ajuda inesperada e Chegando ao serviço de referência - do alívio do atendimento à percepção da existência de novos problemas. Discussão: algumas famílias foram encaminhadas por vínculo de amizade, transferência em vaga zero e procura espontânea em outros serviços de saúde. Após diagnostico e início do tratamento, a família demonstrou esperança na cura, relatando sensação de alívio por perceber a criança sendo assistida. Conclusão: evidenciou-se que crianças com doenças crônicas e suas famílias vivenciam um longo processo de busca de acesso a saúde, principalmente pela necessidade de encaminhamento para hospitais de referência.

Palavras-chave: Família, Acesso aos serviços de saúde, Enfermagem Pediátrica.

\section{Introdução}

A doença crônica é caracterizada por curso lento e progressivo, de longa duração, com recidivas dos sintomas e necessidade de hospitalização por, pelo menos, uma vez ao ano, podendo ser relacionada a múltiplas causas ${ }^{1}$.

Com o aumento da incidência de doenças crônicas não transmissíveis e a consequente redução de doenças agudas em crianças e adolescentes, há a necessidade de compreender como é viver com uma doença crônica e as mudanças que ocorrem no núcleo familiar? ${ }^{2}$.

Diante do exposto, o objetivo desse estudo foi compreender o itinerário terapêutico de famílias de crianças com doenças crônicas hospitalizadas.

\section{Resultados e Discussão}

Trata-se de um estudo fenomenológico, a partir de entrevistas fenomenológicas com 10 famílias de crianças hospitalizadas na Unidade de Internação Pediátrica, de um hospital público, localizado no interior de São Paulo. As entrevistas foram gravadas, transcritas e analisadas, segundo Martins e Bicudo ${ }^{3}$.

A pesquisa obedece aos princípios éticos e foi aprovada sob parecer n. 2.813.225 do Comitê de Ética em Pesquisa da Unicamp e os participantes assinaram o Termo de Consentimento Livre e Esclarecido.

Emergiram quatro categorias temáticas: Caminhando em busca de assistência à saúde do filho - o início da saga; Percebendo-se vulneráveis diante do Sistema Único de Saúde; Da dificuldade para conseguir acesso à saúde à ajuda inesperada e Chegando ao serviço de referência do alívio do atendimento à percepção da existência de novos problemas.

O SUS deve garantir à população acesso aos serviços de saúde, sendo a Atenção Primária de Saúde, a porta de entrada e responsável pelo encaminhamento para serviços de saúde de média e alta complexidade ${ }^{4}$. Com intuito de otimizar os recursos disponíveis, criou-se a Central de Regulação de Oferta de Serviço em Saúde ${ }^{5}$. No entanto, algumas famílias foram encaminhadas por meio de vínculo de amizade, além de transferência por vaga zero ou procura espontânea em outros serviços de saúde.

Durante o itinerário terapêutico, algumas famílias vivenciaram momentos de dificuldades, principalmente relacionado ao apoio familiar. Após diagnostico e início do tratamento, a família demonstrou esperança na cura, relatando sensação de alívio por perceber a criança sendo assistida. Contudo, algumas sentiram-se desrespeitadas pelos profissionais de saúde.

\section{Conclusões}

Evidenciou-se que crianças com doenças crônicas e suas famílias vivenciam um longo processo de busca de acesso a saúde, principalmente quando há necessidade de encaminhamento para hospitais de referência.

\section{Agradecimentos}

Ao Conselho Nacional de Desenvolvimento Científico e Tecnológico (CNPq), Programa Institucional de Bolsas de Iniciação Científica, quota 2018-2019.

\footnotetext{
1. Brasil. Ministério da Saúde. Secretaria de Atenção Básica à Saúde. Departamento de Atenção Básica. Diretrizes para o cuidado das pessoas com doenças crônicas nas redes de atenção à saúde e nas linhas de cuidados prioritárias. Brasília; 2013.

2. Fernandes LTB, Nóbrega VM, Silva MEA, Machado AN, Collet N. Supported self-care for children and adolescents with chronic disease and their families. Rev Bras Enferm. 2017;70(6):1318-29.

3. Martins J, Bicudo MAV. A pesquisa qualitativa em psicologia: fundamentos e recursos básicos. São Paulo: Moraes; 2005.

4. Peiter CC, Lanzoni GMM, Oliveira WF. Regulação em saúde e promoção da equidade: o Sistema Nacional de Regulação e o acesso à assistência em um município de grande porte. Saúde Debate. 2016;40(111):63-73.

5. Ferraz AR, Carreiro MA. Reflexão teórica sobre a regulação de leitos de terapia intensiva em um município do Rio de Janeiro. R. Pró-Uni. 2018;09(1):76-80
} 